\title{
DO PÁTRIO PODER AO PODER FAMILIAR: AS ATRIBUIÇÕES DOS PAIS QUANTO À PROTEÇÃO DOS FILHOS ${ }^{1}$
}

FROM THE HOMELAND POWER TO FAMILY POWER: PARENT'S ASSIGNMENTS AS TO THE PROTECTION OF CHILDREN

Marília Benedini PEREIRA

Frederico Thales de Araújo MARTOS ${ }^{3}$

ISSUE DOI: $10.21207 / 2675-0104.2019 .907$

\section{RESUMO}

Objetiva-se, com o presente artigo científico, fazer uma análise acerca dos deveres dos pais quanto à proteção dos filhos, sob a óptica do princípio da afetividade, impondo-lhes, em caso de descumprimento, as sanções de suspensão ou destituição da autoridade parental. Para isso, examinase, em primeiro lugar, as alterações promovidas pela Constituição Federal de 1988 em matéria de Direito de Família, decorrentes, principalmente, da consagração do axioma da dignidade humana, as quais refletiram em uma verdadeira transformação no modo de interpretação da legislação infraconstitucional, notadamente o Código Civil de 2002 e o Estatuto da Criança e do Adolescente. Passa-se, em seguida, à conceituação e breve elucidação dos estados de filiação biológico e socioafetivo, bem como dos encargos advindos do poder familiar a eles vinculado. Finalmente, examinam-se posições doutrinárias e jurisprudenciais relativas à atuação da Justiça da Infância e

\footnotetext{
${ }^{1} \mathrm{O}$ presente artigo sintetiza a monografia de conclusão da pesquisa, realizada para o Programa Interno de Bolsas de Iniciação Científica (PIBIC 2018-2019) da Faculdade de Direito de Franca (FDF), Franca/SP.

${ }^{2}$ Discente da Faculdade de Direito de Franca (FDF), Franca/SP. Bolsista do Programa Interno de Bolsas de Iniciação Científica (PIBIC 2018-2019).

${ }^{3}$ Doutor em Direito pela Faculdade Autônoma de Direito - FADISP (2014). Professor Concursado e Titular de Direito Civil na Graduação da Faculdade de Direito de Franca - FDF (2016) e na Universidade do Estado de Minas Gerais, unidade de Frutal - UEMG/Frutal (2018). Advogado inscrito na OAB/SP. Associado ao Conselho Nacional de Pesquisa e Pós-Graduação em Direito CONPEDI e Autor de diversos artigos e livros acadêmicos. Desenvolve pesquisa científica.
} 
Juventude na coibição da negligência parental, por meio dos mecanismos previstos nos artigos 1.637 e 1.638 do diploma civil brasileiro.

Palavras-chave: Família. Afetividade. Autoridade parental. Deveres parentais. Sanções.

\section{ABSTRACT}

The aim of this scientific article is to analyse parent's duties regarding to the protection of their children, through the optics of the principle of affectivity, imposing them, in case of unaccomplishment, the sanctions of parental authority's suspension or destitution. In order to do so, we examine, firstly, the alterations promoted by 1988's Federal Constitution in the subject of Family Law, mainly due to the consecration of the human's dignity axiom, which have reflected in a real transformation in the way infraconstitucional legislation is interpreted, notably the 2002's Civil Code and the Child and Youth Statute. Next, the states of biological and socio-affective offspring are conceptualized and elucidated, besides the duties of the family power linked to them. Finally, there is an examination of doctrinal and jurisprudential positions related to the role played by Childhood and Youth Justice as to restrain parental negligence, making use of the mechanisms provided by articles 1.637 and 1.638 of Brazilian's civil diploma.

Keywords: Family. Affectivity. Parental authority. Parental duties. Sanctions.

\section{$1 \quad$ INTRODUÇÃO}

Com a entrada em vigor da democrática e humanizada Constituição Federal de 1988, o Direito de Família experimentou uma verdadeira revolução: novos princípios civil-constitucionais foram inaugurados e a dignidade humana foi alçada à categoria de fundamento do Estado Democrático de Direito, estabelecendo o homem como um fim em si mesmo. Dela, outros princípios irradiaram-se, entre eles, o da igualdade familiar, o da afetividade e da proteção integral à criança e ao adolescente, que se propagaram, ainda que implicitamente, pela essência do Código Civil de 2002 e do Estatuto da Criança e do Adolescente, moldados nos termos da nova Magna Carta.

Como consequência, deu-se uma nova leitura aos conceitos de "filiação" e "poder familiar", à medida que se reconheceu o parentesco formado através da socioafetividade, bem como a igualdade entre o homem e a mulher na condução da entidade familiar. Sob esta perspectiva, objetiva-se mapear, de forma sintética, os deveres dos pais quanto à proteção dos filhos e as sanções relativas ao seu descumprimento, ilustrando-se o tema a partir de posicionamentos doutrinários $\mathrm{e}$ jurisprudenciais e apresentando-se recentíssima alteração legislativa acerca do tema, consubstanciada na Lei 13.715/2018.

Para tanto, recorre-se às metodologias analítico-sintética e dogmático-jurídica, discorrendo-se, brevemente, acerca da evolução do tratamento dado à família no ordenamento jurídico brasileiro, os reflexos 
do afeto no tratamento despendido aos filhos como resultado da autoridade parental a que se vinculam e a atuação da Justiça da Infância e Juventude na coibição da negligência parental pela utilização dos mecanismos de suspensão e destituição do poder familiar.

\section{A EVOLUÇÃO DA FAMÍLIA NO DIREITO BRASILEIRO}

À época do Código Civil de 1916, a noção de "família" se encontrava solidificada no conservadorismo derivado da tradição romana e nas influências do cristianismo. Possuía, assim, como características principais, o patriarcalismo, o formalismo e a hierarquização, na medida em que atribuiu-se ao casamento "a condição de criar a família legítima e de legitimar os filhos comuns antes dele nascidos ou concebidos" se, de forma notadamente discriminatória, distinção entre as posições ocupadas pelo homem, chefe do pátrio poder, e pela mulher, relativamente incapaz, no âmbito da entidade familiar, bem como em relação aos vínculos extramatrimoniais e aos filhos daí havidos, os quais eram tidos como ilegítimos 5 .

Nesse contexto, em que figurava uma verdadeira desigualdade conjugal, os núcleos familiares não matrimonializados não possuíam amparo legal algum e, nos termos do art. 380 do diploma civil anterior, o poder familiar somente poderia ser conferido à mulher, em último caso, caso o marido faltasse ou estivesse impedido de exercê-lo. Os filhos, por seu turno, eram considerados legítimos ou ilegítimos a depender fossem concebidos na constância do casamento civil ou não, sendo que os descendentes de pessoas que eram impedidas a se casar devido à presença de outro matrimônio ou de relação de parentesco - denominados adulterinos ou incestuosos - eram marginalizados e esquecidos, não podendo nem mesmo ser reconhecidos, conforme art. 358.

Quando, enfim, entrou em vigor a Constituição Federal de 1988 - por sinal, a mais democrática e igualitária da história brasileira -, revelouse um verdadeiro "marco divisório da legislação familiar pátria"

\footnotetext{
${ }^{4}$ PIVA, Rui Carvalho. Famílias e Tutela dos Direitos Difusos [livro eletrônico]. São Paulo: Atlas, 2014, p. 85.8 Disponível em: <https://integrada.minhabiblioteca.com.br/\#/books/9788522489688/cfi/0!/4/2@100:0.00〉. Acesso em: 10 jul. 2019.

${ }^{5}$ DIAS, Maria Berenice. Manual de Direito das Famílias. 9. ed. São Paulo: Editora Revista dos Tribunais, 2013, p. 30.

${ }^{6}$ PIVA, Rui Carvalho. op. cit. p. 75, nota 2.
} 
trouxe consigo a inauguração de diversos princípios que irradiaram por toda a legislação existente, promovendo alterações fundamentais no panorama jurídico anterior. Cite-se, brevemente, alguns deles:

a) Princípio da dignidade da pessoa humana: concebido por Gagliano e Pamplona Filho como um "princípio solar em nosso ordenamento" ", é o princípio fundamental do Estado Democrático de Direito que decorre de previsão expressa do art. $1^{\circ}$, III da Constituição Federal, podendo, porém, ser identificado indiretamente em diversos dispositivos do mesmo diploma, tais como os arts. 226, 227 e 230. Significa, no Direito de Família, o tratamento de respeito e integridade que deve ser dispensado reciprocamente no ambiente familiar, compreendendo, sobretudo, o declínio do patriarcalismo e o desenvolvimento saudável dos filhos.

b) Princípio da igualdade familiar: rotulado como um direito fundamental, possui três vertentes, quais sejam, a igualdade entre os cônjuges na constância da sociedade conjugal (arts. $5^{\circ}$, I e $226, \S^{\circ}$ da Constituição Federal), a igualdade relativa aos vínculos de filiação, sejam estes havidos do casamento, extramatrimoniais ou até mesmo por adoção (art. 227, $\S 6^{\circ}$ da Constituição Federal) e a igualdade entre entidades familiares, independentemente de sua modalidade.

c) Princípio da proteção integral à criança e ao adolescente: como dever da família, da sociedade e do Estado, o art. 227 da Constituição Federal assegura a crianças, adolescentes e jovens o direito à vida, à saúde, à alimentação, à educação, ao lazer, à profissionalização, à cultura, à dignidade, ao respeito, à liberdade e à convivência familiar e comunitária, colocando-os a salvo de toda forma de negligência, discriminação, exploração, violência, crueldade e opressão. Destaca Madaleno, dessa forma, que "seria inconcebível admitir pudesse qualquer decisão envolvendo os interesses de crianças e adolescentes fazer tábula rasa do princípio de seus melhores interesses" ${ }^{\text {. }}$.

d) Princípio da afetividade: segundo Tartuce, "o afeto é a mola propulsora dos laços familiares e das relações interpessoais movidas pelo sentimento e pelo amor, para ao fim e ao cabo dar sentido e dignidade à

\footnotetext{
${ }^{7}$ GAGLiAnO, Pablo Stolze; PAMPLONA FILHO, Rodolfo. Novo Curso de Direito Civil: Direito de Família [livro eletrônico]. 7. ed. São Paulo: Saraiva, 2017, p. 80. Disponível em: <https://integrada.minhabiblioteca.com.br/\#/books/9788547217259/cfi/0>. Acesso em: 12 jul. 2019. ${ }^{8}$ MADALENO, Rolf. Direito de Família [livro eletrônico]. 8. ed. Rio de Janeiro: Forense, 2018, p. 99. Disponível em: <https://integrada.minhabiblioteca.com.br/\#/books/9788530980160/cfi/6/2!/4/2@0:0>. Acesso em: 15 jul. 2019.
} 
existência humana"9. Como valor jurídico, representa a consagração da família eudemonista, com base no direito fundamental à felicidade que orienta a atuação do Estado e dos membros da família reciprocamente. Apesar de não estar disposto expressamente na Constituição Federal, pode ser encontrado de forma implícita em diversos dispositivos, como os que preceituam a igualdade da filiação (art. $227, \S 6^{\circ}$ ), que alcança, inclusive, a adoção (art. 227, $\S \S 5^{\circ}$ e $6^{\circ}$ ); a constitucionalidade da união estável (art. $226, \S 3^{\circ}$ ) e da entidade familiar monoparental formada por qualquer dos pais e seus descendentes (art. $226, \S 4^{\circ}$ ); e a convivência familiar como dever da família, da sociedade e do Estado e direito da criança, do adolescente e do jovem (art. 227, caput).

Destarte, no ano de 2003 entrou em vigor o Novo Código Civil Brasileiro, com vistas à regulamentação infraconstitucional das relações civis, através de uma nova roupagem. A regra, agora, seria a da igualdade e, com isso, tomando o afeto como tema central, o diploma civil contemporâneo regulou expressamente a união estável, conceituando-a, no art. 1.723, como "entidade familiar entre o homem e a mulher, configurada na convivência pública, contínua e duradoura e estabelecida com o objetivo de constituição de família", sem embargo de amparo legal a outras espécies familiares.

No que diz respeito à filiação, o art. 1.596 proclama a proibição de designações discriminatórias, ao estabelecer que "os filhos, havidos ou não da relação de casamento, ou por adoção, terão os mesmos direitos e qualificações"10. Tendo em vista o princípio da proteção integral, o Código prevê paridade nos poderes-deveres dos pais no exercício do poder familiar, dispondo expressamente sobre suas obrigações, no art. 1.634.

Ademais, como reflexo às normas constitucionais criou-se um sistema especial de proteção integral à criança e ao adolescente, chamado Estatuto da Criança e do Adolescente (Lei Federal nº 8069/90), aplicável, como disposto nos arts. $1^{\circ} \mathrm{e} 2^{\circ}$, àquelas pessoas compreendidas entre zero e 18 anos da idade. Das principais regras concernente ao direito à convivência familiar e comunitária presentes no Estatuto, decorre, primeiramente, que nos termos dos arts. 19 e 25, toda criança e adolescente

\footnotetext{
${ }^{9}$ TARTUCE, Flávio. Direito Civil: Direito de Família [livro eletrônico]. 13. ed. Rio de Janeiro: Forense, 2018. Disponível em: <https://integrada.minhabiblioteca.com.br/\#/books/9788530978235/cfi/6/2!/4/2@0:0>. Acesso em: 15 jul. 2019.

${ }^{10}$ BRASIL. Lei n. 10.406, de 10 de jan. de 2002. Institui o Código Civil. Diário Oficial da República Federativa do Brasil, Brasília, DF, 11 de jan. de 2002. Disponível em: <http://www.planalto.gov.br/ccivil_03/Leis/2002/110406.htm>. Acesso em: 16 jul. 2019.
} 
tem direito a ser criado e educado no seio de sua família, entendendo-se a família natural como aquela formada pelos pais, ou por qualquer deles e seus descendentes (biparental ou monoparental), sem haver, portanto, qualquer critério discriminatório.

Outrossim, os arts. 20 e 21 enfatizam ainda mais, respectivamente, a igualdade no âmbito da filiação e do poder familiar, sendo que este último, nos termos do art. 23, não será perdido e nem suspenso devido à falta ou carência de recursos materiais, o que reassegura a importância da manutenção do vínculo dos descendentes com sua família natural, com a ressalva do dever de atuação do Estado, nesse sentido, para sua inclusão em programas oficiais de auxílio $\left(\S 1^{\circ}\right)$.

Por sua vez, pormenorizando os deveres contidos no art. $227 \mathrm{da}$ Constituição, preceitua o art. 22 do ECA que aos pais, igualmente responsáveis pelo cuidado dos menores, incumbem os deveres de sustentálos, tê-los sob sua guarda e educá-los. Nesse sentido, o dever de sustento consubstancia-se na obrigação de prover assistência material, que cessa com a maioridade civil atingida aos 18 anos de idade, ou com a emancipação, sem prejuízo da possibilidade de prorrogação.

Por seu turno, a guarda comum ou natural exercida pelos pais em relação aos seus descendentes menores significa, mais do que o direito de tê-los consigo, a responsabilidade de exercer, sobre eles, dever de vigilância. Por fim, a obrigação de proporcionar educação aos filhos exprime a concessão de instrução espiritual e educacional na formação da pessoa humana, com a aplicação de correição e disciplina, sem, contudo, utilizar de tratamentos cruéis ou degradantes.

Destarte, o não cumprimento injustificado dos deveres paternofiliais pode ensejar na perda ou na suspensão do poder familiar, segundo a disposição expressa do art. 24. Conclui-se, assim, que na forma da doutrina da proteção integral a crianças e adolescentes, o cumprimento de tais tarefas representa não só uma competência paterna indelegável, mas, também, um exercício de cidadania, ao passo que sua desobediência é capaz de gerar a ruptura do ambiente familiar sadio. 
Aduz Calderón que "o marco paradigmático do Direito brasileiro que confere reconhecimento jurídico à afetividade, de maneira implícita, é a Constituição Federal de 1988"11. Esta razão de ser deve-se à transformação, pela manifestação social, da família clássica, patriarcal, matrimonializada, e hierarquizada, cujo âmago era a legitimidade, tanto do casamento quanto dos filhos, para a família contemporânea, fundada na isonomia entre cônjuges e filhos e na proteção a todas as entidades familiares, com essência na afetividade e no eudemonismo que colocaram em evidência não o patrimônio, mas sim a realização pessoal do ser humano, em primeiro lugar. Veja-se, a propósito, a lição de Dias:

O novo modelo da família funda-se sobre os pilares da repersonalização, da afetividade, da pluralidade e do eudemonismo, impingindo nova roupagem axiológica ao direito das famílias. Agora, a tônica reside no indivíduo, e não mais nos bens ou coisas que guarnecem a relação familiar. A famíliainstituição foi substituída pela família-instrumento, ou seja, ela existe e contribui tanto para o desenvolvimento da personalidade de seus integrantes como para o crescimento e formação da própria sociedade, justificando, com isso, a sua proteção pelo Estado ${ }^{12}$.

Como consequência, deu-se uma nova leitura ao Código Civil de 2002, voltada para a questão da afetividade. Exemplos são a consagração da igualdade da filiação, no art. 1.596; a permissão do parentesco formado por outra origem que não a biológica, no art. 1.593, pelo qual separou-se as funções de genitor e de pai; e a menção à "comunhão plena de vida" no matrimônio, no art. 1.511, implicando que o casamento não seria apenas direcionado à conservação da família e à procriação, mas também um núcleo orientado ao eudemonismo humano. Incidência há, ainda, no art. $1.584, \S 5^{\circ}$, que se ocupa da atribuição da guarda dos menores em favor de terceiros, quando se refere expressamente à utilização, pelo julgador, do critério da afetividade, aliado ao melhor interesse da criança e do adolescente.

Nota-se que em todos os casos a afetividade é analisada em uma perspectiva objetiva, como fato social de parentalidade ou de conjugalidade, que apenas deixa de existir com o falecimento ou a perda da autoridade parental. De outro lado, observa-se que o legislador tratou do

\footnotetext{
${ }^{11}$ CALDERÓN, Ricardo. Princípio da afetividade no Direito de Família [livro eletrônico]. 2. ed. Rio de Janeiro: Forense, 2017, p. 54. Disponível em: <https://integrada.minhabiblioteca.com.br/\#/books/9788530977153/cfi/6/2!/4/2@0:0>. Acesso em 18 jul. 2019.

${ }^{12}$ DIAS, Maria Berenice. op. cit. p. 33, nota 3.
} 
cuidado como um subprincípio da dignidade humana intimamente ligado à afetividade, uma vez que é através do dever de cuidado que esta se manifesta objetivamente.

Ante o exposto, considerando que "a responsabilidade é a essência do afeto e do cuidado"13, verificar-se-á adiante, como decorrência, que a ausência do cumprimento dos deveres de cuidado pode fundamentar a ocorrência das hipóteses de suspensão e extinção do poder familiar.

\subsection{FILIAÇÃO BIOLÓGICA E SOCIOAFETIVA}

Filiação, no conceito de Lôbo, "é a relação de parentesco que se estabelece entre duas pessoas, uma das quais é titular de autoridade parental e a outra a esta se vincula pela origem biológica ou socioafetiva"14. A filiação biológica e a filiação socioafetiva são, assim, espécies do gênero denominado "estado de filiação".

Dá-se o estado de filiação através da força da convivência familiar e da afetividade, conjugados três requisitos: a nominatio (possuir o filho o sobrenome do pai); a tractatus (ser o filho educado e tratado nessa qualidade); e a reputatio (que o filho seja socialmente reconhecido como tal). Para a doutrina atual, contudo, basta para reconhecimento da constituição do estado de filiação a conjugação dos dois últimos, sendo o tratamento o de maior importância, aferível pelas condutas de proteção, suporte econômico e, sobretudo, afetividade.

Destarte, em face do art. 227 da Constituição Federal e dos arts. 1.593, 1.596 e 1.597 do Código Civil, presume-se haver atualmente três estados de filiação: filiação biológica relativa a ambos os pais, casados ou em união estável, ou em relação a um deles no modelo monoparental; filiação socioafetiva relativa a ambos os pais ou a apenas um deles quando da adoção regular; e filiação socioafetiva perante o pai que consentiu na inseminação artificial heteróloga, sendo que, nos dois últimos casos, a paternidade socioafetiva gera os mesmos direitos pessoais e patrimoniais

\footnotetext{
${ }^{13}$ PEREIRA, Rodrigo da Cunha. Responsabilidade Civil Pelo Abandono Afetivo. In: MADALENO, Rolf; BARBOSA, Eduardo (Coords.). Responsabilidade civil no Direito de Família [livro eletrônico]. São Paulo: Atlas, 2015, p. 404. Disponível em: <https://integrada.minhabiblioteca.com.br/\#/books/9788597000689/cfi/0!/4/2@100:0.00>. Acesso em: 20 jul. 2019.

${ }^{14}$ LÔBO, Paulo. Direito Civil: famílias [livro eletrônico]. 7. ed. São Paulo: Saraiva, 2017. Disponível em: <https://integrada.minhabiblioteca.com.br/\#/books/9788547209865/cfi/0>. Acesso em: 22 jul. 2019.
} 
da paternidade biológica. Sem embargo, ressalte-se que, atualmente, é comum, ainda, a existência de paternidade socioafetiva nos casos dos chamados "filhos de criação", por meio de reconhecimento judicial ou voluntário.

Nota-se, portanto, que gradualmente consolidou-se a noção de que "a paternidade deve ser vista como um ato de amor e desapego material, e não simplesmente como fenômeno biológico e científico" "15, ao passo que os papéis de genitor e de pai nem sempre coincidem na mesma pessoa. Abandonou-se, assim, o panorama essencialmente biológico que vigorava anteriormente, reconhecendo-se o afeto e a convivência como atos de vontade intrinsecamente ligados à voluntariedade e à pluralidade familiar contemporânea.

\subsection{A AUTORIDADE PARENTAL}

$\mathrm{O}$ poder familiar, ou autoridade parental, passou por significativas evoluções que refletiram a campanha pela igualdade de gênero. O Código Civil de 1916 baseava-se exclusivamente no chamado "pátrio poder", em que o marido, chefe da sociedade conjugal, era responsável pela tomada de todas as decisões relativas à família. Somente com a Constituição Federal de 1988 conferiu-se plena isonomia de gênero e de direitos e atribuições na gerência do poder familiar (arts. $5^{\circ}$, I e 226, $\left.\S 5^{\circ}\right)$, acarretando mudanças substanciais na legislação infraconstitucional à época vigente.

Deste modo, o poder familiar, como concebido hodiernamente, constitui-se não apenas como um poder de ambos os pais, mas sim como uma obrigação legal a eles imposta na observância do interesse dos filhos. É, assim, um dever "irrenunciável, intransferível, inalienável e imprescritível"16, nos planos material e afetivo, que decorre tanto da filiação biológica quanto da filiação socioafetiva, sendo exercida por ambos os pais, em igualdade de condições (arts. $226, \S 5^{\circ}$, CF; 21, ECA e 1634 , caput, CC), ou por um deles, na falta do outro (art. 1.690, CC) até os filhos completarem 18 anos ou serem emancipados antes disso.

\footnotetext{
${ }^{15}$ VENOSA, Sílvio de Salvo. Direito Civil: família [livro eletrônico]. 18. ed. São Paulo: Atlas, 2018, p. $266 . \quad$ Disponível em: <https://integrada.minhabiblioteca.com.br/\#/books/9788597014860/cfi/6/2!/4/2@0:0>. Acesso em: 22 jul. 2019.

${ }^{16}$ DIAS, Maria Berenice. op. cit. p. 436, notas 3 e 10.
} 
Apesar do Código Civil fazer referência, no art. 1.631, apenas à autoridade parental exercida durante o casamento ou união estável, não se pode olvidar de sua aplicabilidade também às demais entidades familiares existentes. É nesse sentido a lição que nos oferece Lôbo:

O Código Civil refere-se apenas à titularidade dos pais, durante o casamento ou a união estável, restando silente quanto às demais entidades familiares tuteladas explícita ou implicitamente pela Constituição. Ante o princípio da interpretação em conformidade com a Constituição, a norma deve ser entendida como abrangente de todas as entidades familiares, onde houver quem exerça o múnus, de fato ou de direito, na ausência de tutela regular, como se dá com irmão mais velho que sustenta os demais irmãos, na ausência de pais, ou de tios em relação a sobrinhos que com ele vivem. $^{17}$

Quanto ao exercício do poder familiar, sem embargo dos deveres estabelecidos nos arts. 227 e 229 da Constituição Federal e do art. 22 do Estatuto da Criança e do Adolescente, já explicitados, elenca o Código Civil, no art. 1.634, outros encargos de suma importância. Sob este prisma, o inciso I do artigo em análise dispõe sobre a preparação dos menores, pelos pais, para a vida social, nos âmbitos físico, psíquico e espiritual, utilizando-se, quando necessário, de métodos corretivos proporcionais.

Por sua vez, ensina Lienhard, citado por Lôbo, que o dever de guarda unilateral ou compartilhada, expresso no inciso II, "permite submeter a criança à vigilância sobre a organização de seu cotidiano e em controlar seus deslocamentos, suas relações com os membros da família e

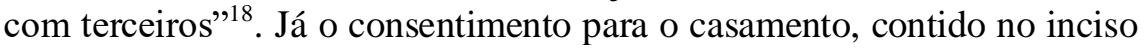
III, aplica-se quando os filhos são maiores de 16 e menores de 18 anos, levando-se em consideração seu nível de amadurecimento, autonomia e responsabilidade.

Além disso, deve-se a ambos os pais, conforme o inciso IV, a autorização para que os menores possam viajar ao exterior, mesmo tratando-se de guarda unilateral, visto que "o não exercício da guarda compartilhada não implica, necessariamente, a perda do poder familiar"19 e, ainda, a permissão para a mudança de residência fixa para outro município (inciso V). Compete-lhes, também, a tutela testamentária para

\footnotetext{
${ }^{17}$ LÔBO, Paulo. op. cit. p. 291, nota 12.

${ }^{18}$ Id., Ibid., p. 295.

${ }^{19}$ GONÇALVES, Carlos Roberto. Direito Civil Brasileiro: Direito de Família [livro eletrônico]. 15. ed. São Paulo: Saraiva, 2018, p. 420. Disponível em: <https://integrada.minhabiblioteca.com.br/\#/books/9788547229320/cfi/0!/4/2@100:0.00>. Acesso em: 22 jul. 2019.
} 
nomeação de tutor (inciso VI), quando o outro titular da autoridade parental for morto ou não puder exercitá-la devido a alguma incapacidade.

Finalmente, incumbe aos pais a representação judicial e extrajudicial dos filhos até os 16 anos e a assistência, entre os 16 e os 18 anos (inciso VII), tendo em vista o suprimento das situações de incapacidade absoluta e relativa (arts. $3^{\circ}$ e $4^{\circ}, C C$ ). Caso os menores sejam ilegalmente detidos por alguém, caberá aos encarregados da autoridade parental o ônus de reclamá-los (inciso VIII). Por último, através da obrigação de exigir obediência e respeito (inciso IX), é possível contribuir para o desenvolvimento da experiência dos filhos, atribuindo-lhes tarefas compatíveis com as suas forças, aptidão e tempo disponível ${ }^{20}$.

Registra-se, primeiramente, que tais poderes-deveres devem ser exercidos em observância às normas legais, ao passo que nos casos de abuso ou violação, podem os pais ter a autoridade parental suspensa ou extinta. Em segundo lugar, verifica-se que a despeito de contemplar obrigações de assistência material, como, aliás, já fazia o Código de 1916, a atual legislação civil omitiu referência a outro múnus igualmente primordial: o de proporcionar aos filhos o amor e o afeto de que são dignos, propiciados pela convivência familiar.

Em decorrência, preceitua o art. 1.636 do diploma em estudo que os genitores que contraem novo casamento ou união estável, não perdem os direitos do poder familiar quanto aos filhos do relacionamento anterior. Daí se extrai que a autoridade parental e o estado civil dos pais são completamente indissociáveis, pois o melhor interesse dos filhos se sobrepõe à relação dos genitores.

Com efeito, formalizada a separação, divórcio ou dissolução da união estável entre os pais, é indispensável a definição dos regimes de guarda e visitação a serem adotados, consensualmente ou mediante decreto do Juiz (art. 1.584, incisos I e II do Código Civil). Seja qual for o arranjo eleito, todavia, é constitucionalmente assegurada aos menores a manutenção do contato com o genitor com que não convivem diariamente. Destaque-se, contudo, que mesmo se tratando de guarda unilateral, o parágrafo $5^{\circ}$ do art. 1.583 da legislação civil deixa clara a locução de que, aquele que não a detém, não se desobriga do ônus da supervisão acerca do atendimento aos interesses dos filhos.

\footnotetext{
${ }^{20}$ NADER, Paulo. Curso de Direito Civil: Direito de Família [livro eletrônico]. 7. ed. Rio de Janeiro: Forense, 2016. Disponível em: <https://integrada.minhabiblioteca.com.br/\#/books/9788530968687/cfi/6/2!/4/2/2@0:0>. Acesso em: 22 jul. 2019.
} 
Nesse sentido, esclarece Dias que a popular expressão "direito de visitas" é inadequada, na medida em que "os encargos inerentes ao poder familiar não se limitam a assegurar ao genitor o direito de ter o filho em sua companhia em determinados períodos de tempo"21. Mais do que mero protocolo a ser seguido, portanto, a convivência pressupõe, também, uma homenagem à unidade familiar, que recomenda a tentativa, ao máximo, da preservação do conjunto de relações de afeto, cuidado, ética e respeito entre os membros da família.

Isto posto, constata-se que o poder familiar é hoje considerado, por sua natureza funcional, como um poder-dever recíproco entre os pais, conjuntamente, e os filhos: o direito de um corresponde ao dever do outro. Não se limita, assim, à mera assistência material, compreendendo, sobretudo, a afetividade. Conserva-se, pois, ao mesmo tempo, o eudemonismo e a solidariedade familiar, que devem prosperar tendo em vista a criação de um ambiente saudável para o crescimento de crianças e adolescentes.

\section{SANÇÕES AO DESCUMPRIMENTO DOS DEVERES PARENTAIS}

Inobstante a recomendação da não interferência estatal na gerência da família (art. 1.513 do Código Civil), examinar-se-á que o Estado reserva, para si, o direito de fiscalizar o atendimento às necessidades básicas dos menores, visando sua proteção e melhor interesse. Assim, constatada a existência de prejuízo à integridade física e psíquica da prole, autoriza-se a intervenção destinada à suspensão ou extinção da autoridade parental, notadamente pela atuação da Justiça da Infância e Juventude.

A começar pela medida menos gravosa, dá-se a suspensão do poder familiar, de acordo com o art. 1.637 do Código Civil, "se o pai, ou a mãe, abusar de sua autoridade, faltando aos deveres a eles inerentes ou arruinando os bens dos filhos (...)"22. Sem prejuízo, o mesmo se aplica nas hipóteses de provocação de riscos à segurança dos menores ou de

\footnotetext{
${ }^{21}$ DIAS, Maria Berenice. op. cit. p. 459, notas 3, 10 e 14.

${ }^{22}$ BRASIL. Lei n. 10.406, de 10 de jan. de 2002. Institui o Código Civil. Diário Oficial da República Federativa do Brasil, Brasília, DF, 11 de jan. de 2002. Disponível em: <http://www.planalto.gov.br/ccivil_03/Leis/2002/110406.htm>. Acesso em: 25 jul. 2019.
} 
condenação dos genitores a crime cuja pena exceda a dois anos de prisão, tal como previsto no parágrafo único do dispositivo ora em estudo.

Essencialmente, conforme demonstrado nos tópicos anteriores, três são os deveres parentais indispensáveis: educação, guarda e sustento dos filhos. Acerca do último, contudo, cabe aqui relembrar, em homenagem ao princípio da afetividade, que a simples carência de recursos financeiros, tal como previsto no art. 23 do ECA, não importa em automática suspensão ou extinção deste múnus.

Nader:

Sem embargo da descrição imprecisa do diploma civil, ensina

Abusar da autoridade é impor sacrifícios desnecessários aos filhos, causando-lhes constrangimentos. Abusar significa ir além do admissível. A autoridade é conferida para o fim de promover a criação e o desenvolvimento físico, moral e intelectual da criança e do adolescente, não para atos de maldade ou de mero capricho ${ }^{23}$.

Por conseguinte, tem-se como exemplos de condutas aptas a ensejar a suspensão do poder familiar: a privação dos filhos de cuidados indispensáveis, a vedação aos períodos de lazer e a sua colocação em ocupações impróprias ou além de sua capacidade. Nota-se, desta forma, que é desnecessária a ocorrência de causa permanente, bastando a implementação de qualquer acontecimento que se enquadre no conceito acima transcrito.

Por tal motivo, é decorrência lógica que a sanção em apreço possa ser aplicada de forma total ou parcial, ou seja, em relação a todos os poderes-deveres paternos ou a apenas alguns deles. Ademais, trata-se de medida facultativa e reversível, de modo que cessada circunstância que lhe deu origem, é de praxe a reapreciação do caso concreto pelo Juiz, podendo o impedido voltar a exercer a autoridade parental, até mesmo sem ressalvas.

Destaque-se, oportunamente, o acertado entendimento Egrégio Tribunal de Justiça do Rio Grande do Sul:

APELAÇÕES CÍVEIS. AÇÃO DE DESTITUIÇÃO DO PODER FAMILIAR. MANUTENÇÃO DA SENTENÇA. OPÇÃO PELA SUSPENSÃO DO PODER FAMILIAR. EXISTÊNCIA DE VÍNCULO AFETIVO. POSSIBILIDADE DE REINTEGRAÇÃO DOS ADOLESCENTES À FAMÍLIA BIOLÓGICA. 1. Quatro são as hipóteses de suspensão do poder familiar: (a) descumprimento dos deveres a eles (pais) inerentes; (b) ruína dos bens dos filhos; (c)

${ }^{23}$ NADER, Paulo. op. cit. p. 406, nota 18. 
risco à segurança do filho e (d) condenação em virtude de crime cuja pena exceda a dois anos de prisão. Não é preciso que a causa seja permanente, bastando só um acontecimento, que justifique o receio de vir a se repetir no futuro com risco para a segurança do menor, para ensejar a suspensão. 2. No caso em tela, a genitora incorreu pelo menos em duas dessas hipóteses, vez que descumpriu os seus deveres inerentes e colocou em risco a segurança dos infantes. 3. No entanto, contrariamente a muitos outros casos de perda/suspensão do poder familiar, a genitora vem efetivando movimentos importantes para o resgate das condições psicossociais necessárias ao bom desempenho das funções parentais. 4. A suspensão do poder familiar ou a adoção de outras medidas eficazes devem ser sempre preferidas à perda do poder familiar, a não ser que os atos cometidos pelos genitores sejam de tal gravidade a justificar esta medida extrema. Assim, antes de determinar a destituição do poder familiar, imperioso que se esgotem as possibilidades de reinserção dos infantes à sua família biológica, o que só será viável com a provisoriedade inerente à suspensão do poder familiar. NEGARAM PROVIMENTO A AMBOS OS RECURSOS. UNÂNIME. ${ }^{24}$

De outro lado, a extinção do poder familiar, embora não resulte no rompimento dos laços de parentesco entre os genitores e sua prole, pode se configurar, na leitura do art. 1.635 do Código Civil brasileiro, de três formas: naturalmente, voluntariamente (ou de pleno direito) ou através de decisão judicial. De forma sintética, a extinção por fato natural ocorre quando há a morte de dos pais ou dos filhos (inciso I) ou a maioridade destes últimos (inciso III). De outro lado, a autoridade parental extinguese de modo voluntário pela entrega dos menores, pelos pais, para adoção (inciso IV) ou, ainda, através da emancipação (inciso II). Interessa ao presente trabalho, todavia, a hipótese de perda judicial do poder familiar, sobre a qual se discorrerá.

Resultam na perda ou destituição judicial da autoridade parental as condutas descritas no art. 1.638 da legislação civil. A referência aos castigos imoderados (inciso I) comporta divergências doutrinárias. Sustenta Nader que tal regra visa permitir a atuação dos genitores com vistas a corrigir os filhos, apenas caracterizando infração a este dever a aplicação de castigos excessivos ${ }^{25}$. Sob outra perspectiva, filia-se

\footnotetext{
${ }^{24}$ BRASIL. Tribunal de Justiça do Rio Grande do Sul. Apelação Cível n. ${ }^{\circ} 70070290283.8^{\text {a }}$ Câmara Cível. Apelante: T.C.R. Apelado: M.P. Relator: Desembargador Luiz Felipe Brasil Santos. Porto Alegre, $\quad$ RS, 27 out. 2016.2 Disponível em: $<$ https://www 1.tjrs.jus.br/site_php/consulta/consulta_processo.php?nome_comarca=Tribunal $\% 20 \mathrm{de} \%$ 20Justi $\% \mathrm{C} 3 \% \mathrm{~A} 7 \mathrm{a} \% 20 \mathrm{do} \% 20 \mathrm{RS} \& \mathrm{versao}=\&$ versao_fonetica $=1 \&$ tipo $=1 \& \mathrm{id} \_$comarca $=700 \&$ num_pro cesso_mask $=\&$ num $\_$processo $=70070290283 \&$ codEmenta $=7706337 \&$ temIntTeor $=$ true $>$. Acesso em: 25 jul. 2019.

${ }^{25}$ NADER, Paulo. op. cit. p. 403, notas 18 e 21.
} 
Gonçalves à corrente que sustenta não serem admissíveis, face ao princípio da dignidade humana, quaisquer castigos, sob pena de configurarem abuso de autoridade paterna ${ }^{26}$.

Já o abandono (inciso II), não se configura exclusivamente pelo desamparo físico e material, mas também através da negligência quanto aos cuidados psíquicos e emocionais. É o que se depreende do Acórdão proferido pelo Egrégio Tribunal de Justiça do Distrito Federal e Territórios:

PROCESSUAL CIVIL. DIREITO DA INFÂNCIA E DA JUVENTUDE. AÇÃO DE DESTITUIÇÃO DO PODER FAMILIAR REQUERIDA PELO MINISTÉRIO PÚBLICO. SENTENÇA DE PROCEDÊNCIA DO PEDIDO INICIAL. MENORES EM ABRIGO POR MAIS DE 10 ANOS. SITUAÇÃO DE ABANDONO MATERIAL E AFETIVO CARACTERIZADA. CARÁTER PUNITIVO DA DECISÃO. INOCORRÊNCIA. APELAÇÃO. RECURSO DESPROVIDO. 1Recurso de apelação interposto em face de sentença que julgou procedente o pedido inicial para decretar a perda do poder familiar do apelante em relação a seus filhos menores. 2- Da análise detalhada do conjunto probatório acostado aos autos, mormente do documento técnico, conclui-se claramente, que o réu agiu de forma desairosa e negligente para com seus filhos, que se encontram em abrigo desde novembro de 2001 sendo que nesse período o apelante os visitou esporadicamente. 3- A negligência do apelante quanto aos cuidados inerentes ao exercício do poder familiar, como a assistência material e afetiva aos filhos encontra-se evidenciada nos autos. Nos termos do art. 1.638, inciso II do código civil perderá por ato judicial o poder familiar o pai ou a mãe que: deixar o filho em abandono. 4- No caso em análise, o descuido do apelante em relação aos filhos, não deflui tão somente da escassez de bens materiais, decorre principalmente do abandono afetivo, que pode causar severos danos à criança. 5- A perda do poder familiar é medida extrema, mas deve ser deferida quando os pais não apresentam condições de exercer tal mister e não restam outros caminhos a preservar os interesses dos incapazes. 6- O decreto de perda do poder familiar não se reveste de caráter eminentemente punitivo como afirma o recorrente. A rigor, o decreto se deu visando à proteção dos menores que, na prática, já estavam sem o apoio dos pais. 7- Recurso desprovido. ${ }^{27}$

\footnotetext{
${ }^{26}$ GONÇALVES, Carlos Roberto. op. cit. p. 428, nota 17.
}

27 BRASIL. Tribunal de Justiça do Distrito Federal e dos Territórios. Apelação Cível n. ${ }^{\circ}$ 20070130040343. 5 Turma Cível. Apelante:. Apelado:. Relator: Desembargador João Egmont. Distrito Federal, DF. 09 fev. 2012. Disponível em: <https://pesquisajuris.tjdft.jus.br/IndexadorAcordaos$\mathrm{web} /$ sistj?visaoId=tjdf.sistj.acordaoeletronico.buscaindexada.apresentacao.VisaoBuscaAcordao\&nom eDaPagina=buscaLivre2\&buscaPorQuery $=1 \&$ baseSelecionada=BASE_ACORDAOS\& filtroAcordao sPublicos $=$ false $\&$ camposSelecionados $=[$ ESPELHO]\&argumentoDePesquisa $=0003971412007807001$ $3 \&$ numero $=\&$ tipoDeRelator $=$ TODOS $\&$ dataFim $=\&$ indexacao $=\&$ ramoJuridico $=\&$ baseDados $=[$ TURM AS_RECURSAIS,\%20BASE_ACORDAOS_IDR,\%20BASE_ACORDAOS]\&tipoDeNumero=Num Acordao\&tipoDeData $=$ DataPublicacao\&ementa $=\&$ filtroSegredoDeJustica $=$ false $\&$ desembargador $=\&$ 
Acerca da moral e dos bons costumes (inciso III), tem-se que estes "são aferidos objetivamente, segundo standards valorativos predominantes na comunidade, no tempo e no espaço, incluindo as condutas que o direito considera ilícitas"28. Isto, pois é dos pais o encargo de educar e guiar os filhos pelos caminhos corretos, desde seus primeiros anos de vida. Além disso, no inciso IV do dispositivo em apreço, deixa claro o legislador a ideia de gradação e enrijecimento das sanções, de modo que reiteradas suspensões podem resultar em eventual destituição da autoridade parental.

Por sua vez, a hipótese de entrega irregular do filho a terceiros para fins de adoção (inciso V) constitui novidade acrescentada pela Lei n. 13509/2017. Todavia, em julgamento recente, transcrito abaixo, entendeu o Colendo Superior Tribunal de Justiça que a norma não poderia retroagir automaticamente, sendo necessária a análise da configuração da adoção à brasileira no caso concreto. Veja-se:

CIVIL. RECURSO ESPECIAL. RECURSO INTERPOSTO SOB A ÉGIDE DO NCPC. FAMÍLIA. AÇÃO DE DESTITUIÇÃO DE PODER FAMILIAR EM RAZÃO DE INDÍCIOS DA PRÁTICA DE "ADOÇÃO À BRASILEIRA". SENTENÇA DE PROCEDÊNCIA. DESCONSTITUIÇÃO DO PODER FAMILIAR. PROCEDIMENTO PARA COLOCAÇÃO DA MENOR EM FAMÍLIA SUBSTITUTA. ALEGADA OCORRÊNCIA DE CERCEAMENTO DE DEFESA EM VIRTUDE DO INDEFERIMENTO DA REALIZAÇÃO DO ESTUDO SOCIAL E AVALIAÇÃO PSICOLÓGICA. OBSERVÂNCIA DOS PRINCÍPIOS PROTETIVOS DA CRIANÇA E DO ADOLESCENTE NA INTERPRETAÇÃO DAS NORMAS. "ADOÇÃO À BRASILEIRA" NÃO ERA HIPÓTESE PREVISTA PARA DESTITUIÇÃO DO PODER FAMILIAR AO TEMPO DA AÇÃO E DA SENTENÇA. IMPRESCINDIBILIDADE DA REALIZAÇÃO DO ESTUDO PSICOSSOCIAL EM HIPÓTESE DE DESTITUIÇÃO DE PODER FAMILIAR. RECURSOS ESPECIAIS PARCIALMENTE PROVIDOS PARA ANULAR A SENTENÇA. 1. Aplicabilidade das disposições do NCPC, no que se refere aos requisitos de admissibilidade do recurso especial ao caso concreto ante os termos do Enunciado Administrativo $\mathrm{n}^{\circ} 3$ aprovado pelo Plenário do STJ na sessão de 9/3/2016: Aos recursos interpostos com fundamento no $\mathrm{CPC} / 2015$ (relativos a decisões publicadas a partir de 18 de março de 2016) serão exigidos os requisitos de admissibilidade recursal na forma do novo CPC. 2. A controvérsia consiste em saber se a decretação da perda do poder familiar da mãe biológica em razão suposta entrega da filha para

dataInicio $=\&$ legislacao $=\&$ orgaoJulgador $=\&$ numeroDaPaginaAtual $=1 \&$ quantidadeDeRegistros $=20 \& \mathrm{t}$ otalHits $=1>$. Acesso em 26 jul. 2019.

${ }^{28}$ LÔBO, Paulo. op. cit. p. 300, notas 12 e 15. 
adoção irregular, chamada "adoção à brasileira", prescindia da realização do estudo social e avaliação psicológica das partes litigantes. 3. Por envolver interesse de criança, a questão deve ser solucionada com observância dos princípios da proteção integral e do melhor interesse dela e do adolescente, previstos na Constituição Federal e no Estatuto da Criança e do Adolescente. 4. Para constatação da "adoção à brasileira", em princípio, o estudo psicossocial da criança, do pai registral e da mãe biológica não se mostra imprescindível. Contudo, como o reconhecimento de sua ocorrência ("adoção à brasileira") foi fator preponderante para a destituição do poder familiar, à época em que a entrega de forma irregular do filho para fins de adoção não era hipótese legal de destituição do poder familiar, a realização da perícia se mostra imprescindível para aferição da presença de causa para a excepcional medida de destituição e para constatação de existência de uma situação de risco para a infante, caracterizando cerceamento de defesa o seu indeferimento na origem. 6. Recursos especiais parcialmente providos. ${ }^{29}$

Pode-se dizer, desta forma, que a perda ou destituição do poder familiar é imperativa e permanente, malgrado não seja definitiva, visto que os genitores podem recuperá-lo por meio de processo judicial. Mais do que simples função punitiva, portanto, as sanções ao descumprimento dos deveres parentais possuem, sobretudo, evidente finalidade de garantir fiel observância ao princípio do melhor interesse da criança e do adolescente.

\subsection{AS NOVIDADES DA LEI № $13.715 / 18$}

Recentíssima inovação legislativa em matéria de proteção aos filhos menores, a Lei no 13715/18, sancionada pelo Ministro do Colendo Supremo Tribunal Federal, Dias Toffoli, então Presidente da República em exercício, trouxe importantes alterações em matéria de ampliação das hipóteses de perda do poder familiar pelo sujeito ativo de crimes contra outrem igualmente titular da autoridade parental, filhos ou outros descendentes.

Para tanto, as novidades se estenderam desde o Código Civil e o Estatuto da Criança e do Adolescente, até mesmo ao Código Penal, como

\footnotetext{
${ }^{29}$ BRASIL. Superior Tribunal de Justiça. Recurso Especial n. ${ }^{\circ} 1674207$ PR 2017/0120487-1. Terceira Turma. Recorrente: R. P. dos S., por si e representando A. dos S. R., H. P. dos S. e K. P. dos S. Recorrido: Ministério Público do Estado do Paraná. Relator: Ministro Moura Ribeiro. Brasília, DF, 17 abr. 2018. Disponível em: $<$ https://ww2.stj.jus.br/processo/revista/inteiroteor/?num_registro $=201701204871 \& d t \_$publicacao $=24$ /04/2018>. Acesso em 26 jul 2019.
} 
se examinará a seguir. Tem-se assim, em primeiro lugar, que ao art. 1.638 do diploma civil, foi acrescentado o dispositivo:

\footnotetext{
Parágrafo único. Perderá também por ato judicial o poder familiar aquele que:

I - praticar contra outrem igualmente titular do mesmo poder familiar:

a) homicídio, feminicídio ou lesão corporal de natureza grave ou seguida de morte, quando se tratar de crime doloso envolvendo violência doméstica e familiar ou menosprezo ou discriminação à condição de mulher;

b) estupro ou outro crime contra a dignidade sexual sujeito à pena de reclusão;

II - praticar contra filho, filha ou outro descendente:

a) homicídio, feminicídio ou lesão corporal de natureza grave ou seguida de morte, quando se tratar de crime doloso envolvendo violência doméstica e familiar ou menosprezo ou discriminação à condição de mulher;

b) estupro, estupro de vulnerável ou outro crime contra a dignidade sexual sujeito à pena de reclusão. ${ }^{30}$
}

Acerca do dispositivo em apreço, ensina Cunha que "podemos traçar um paralelo com a condição de indignidade que exclui da sucessão os herdeiros que houverem sido autores, coautores ou partícipes de homicídio doloso contra a pessoa de cuja sucessão se tratar, seu cônjuge, companheiro, ascendente ou descendente" ${ }^{\prime 1}$. Ora, se o bem jurídico protegido pela norma é a integridade física e psicológica dos menores, nada mais acertado do que a destituição do encargo àqueles que se revelem inaptos para exercê-lo.

Ademais, o parágrafo $2^{\circ}$ do art. 23 do ECA passou a vigorar com a seguinte redação:

\begin{abstract}
A condenação criminal do pai ou da mãe não implicará a destituição do poder familiar, exceto na hipótese de condenação por crime doloso sujeito à pena de reclusão contra outrem igualmente titular do mesmo poder familiar ou contra filho, filha ou outro descendente ${ }^{32}$.
\end{abstract}

\footnotetext{
${ }^{30}$ BRASIL. Lei n. 10.406, de 10 de jan. de 2002. Institui o Código Civil. Diário Oficial da República Federativa do Brasil, Brasília, DF, 11 de jan. de 2002. Disponível em: <http://www.planalto.gov.br/ccivil_03/Leis/2002/110406.htm>. Acesso em: 26 jul. 2019.

${ }^{31}$ CUNHA, Rogério Sanches. Nova lei amplia as hipóteses de perda do poder familiar. Ministério Público do Paraná. Disponível em: <http://www.crianca.mppr.mp.br/2018/09/39/LEGISLACAONova-lei-amplia-as-hipoteses-de-perda-do-poder-familiar.html>. Acesso em: 27 jul. 2019.

${ }^{32}$ BRASIL. Lei n. 8.069, de 13 de jul. de 1990. Dispõe sobre o Estatuto da Criança e do Adolescente e dá outras providências. Diário Oficial da República Federativa do Brasil, Brasília, DF, 16 de jul.
} 
Válido ressaltar que esta regra também se aplica à prática de infrações penais por tutores ou curadores, contra seus tutelados e curatelados, além de abarcar outros descendentes, tais como os netos. É o que se depreende da modificação feita no art. 92 da legislação penal que, de forma reflexa, passa a prever, como efeito da condenação, no inciso II, "a incapacidade para o exercício do poder familiar, da tutela ou da curatela nos crimes dolosos sujeitos à pena de reclusão cometidos contra outrem igualmente titular do mesmo poder familiar, contra filho, filha ou outro descendente ou contra tutelado ou curatelado",33.

Sem prejuízo, a novidade, além de finalmente substituir a arcaica expressão "pátrio poder" pelo atual "poder familiar", demonstrou evidente mecanismo de enfrentamento à violência doméstica, seja contra o homem ou a mulher, ao reprimir o cometimento de agressões àquele (a) que, da mesma forma, detém a autoridade parental. Ressalte-se que incidência da perda do poder familiar como efeito da condenação criminal, todavia, não é automática, por força do próprio parágrafo único do art. 92 da legislação penal. Da mesma forma, a reabilitação que, em geral, extingue os efeitos secundários extrapenais da sentença condenatória, não o faz no caso em estudo, conforme a previsão do art. 93, parágrafo único do mesmo diploma.

Além disso, assinala Rizzardo, sabiamente, que "a perda do poder familiar em relação a um filho se estende aos demais. Com efeito, se o pai ou a mãe não revela condições para exercer o cargo relativamente a um filho, é evidente que não tenha capacidade quanto aos demais" ${ }^{\prime 34}$. Isto, pois considera-se o encargo como um todo, e não apenas relativamente a algum dos menores.

Ante o exposto, conclui-se que, por intermédio da Lei $\mathrm{n}^{\circ}$ 13715/18, deu-se uma nova interpretação à competência para o exercício do poder familiar, que passou a ser compreendida de maneira mais expansiva, englobando não apenas as condutas dos pais em relação aos filhos, mas, também, o tratamento dispensado pelos genitores entre si.

de 1990. Disponível em: 〈http://www.planalto.gov.br/ccivil_03/Leis/18069.htm〉. Acesso em: 27 jul. 2019.

33 Decreto-Lei n. 2.848, de 07 de dez. de 1940. Código Penal. Diário Oficial da República Federativa do Brasil, Rio de Janeiro, RJ, 31 de dez. de 1940. <http://www.planalto.gov.br/ccivil_03/decreto-lei/del2848compilado.htm>. Acesso em: 27 jul 2019 ${ }^{34}$ RIZZARDO, Arnaldo. Direito de Família [livro eletrônico]. 10. ed. Rio de Janeiro: Forense, 2019, p. $567 . \quad$ Disponível em: <https://integrada.minhabiblioteca.com.br/\#/books/9788530983062/cfi/6/2!/4/2@0:0>. Acesso em: 30 jul. 2019. 


\section{5}

\section{CONSIDERAÇÕES FINAIS}

Quando a dignidade humana se tornou a preocupação central da ordem jurídica, trouxe consigo a valorização da afetividade nas relações familiares, transformando a perspectiva da família matrimonializada, calcada na formalidade patriarcal, para outra de caráter informal, igualitário e eudemonista, visando a realização de seus integrantes, pessoal e conjuntamente.

Assim, por meio da presente pesquisa-se, buscou-se descrever a trajetória da família no Direito Brasileiro, desde a época em que vigorava o Código Civil de 1916, até a inauguração da Constituição Federal de 1988 e a elaboração do Estatuto da Criança e do adolescente e do diploma civil de 2002. Sem prejuízo, refletiu-se acerca da evolução da sociedade em matéria de Direito de Família, que culminou no reconhecimento os filhos - independentemente de sua origem - como pessoas em desenvolvimento que, por sua própria condição, são dignos de proteção integral.

Destarte, explanou-se os deveres parentais de sustento, guarda e educação da prole, através de uma nova interpretação, levando-se em conta não apenas o prisma material, mas, também, as especificidades englobadas pelo valor jurídico do cuidado. Ademais, mapeou-se, em linhas gerais, as principais características dos institutos da suspensão e destituição da autoridade parental como mecanismos de combate a situações de indiligência quanto aos menores, tecendo-se breves considerações sobre as novidades trazidas pela Lei n. 13715/18.

Ante todo o exposto, conclui-se que, inobstante o estabelecimento, pelo legislador, da responsabilidade parental como corolário da proteção à criança e ao adolescente, na prática, infelizmente, ainda se verificam inúmeros casos de verdadeira displicência parental. Extrai-se, daí, a essencialidade da atuação do Poder Judiciário no exame do integral cumprimento, pelos pais, dos encargos a que estão forçosamente vinculados e, principalmente, na coibição de sua transgressão, de forma a enaltecer a concepção da entidade familiar como base formadora da sociedade.

\section{REFERÊNCIAS BIBLIOGRÁFICAS}

BRASIL. Constituição (1988). Constituição da República Federativa do Brasil. Brasília, DF: Senado Federal, 1988. 
Decreto-Lei n. 2.848, de 07 de dez. de 1940. Código Penal. Diário Oficial da República Federativa do Brasil, Rio de Janeiro, RJ, 31 de dez. de 1940. Disponível em: <http://www.planalto.gov.br/ccivil_03/decreto-lei/del2848compilado.htm>. Acesso em: 27 jul 2019.

. Lei n. 3.071, de $1^{\circ}$ de jan. de 1916. Código Civil dos Estados Unidos do Brasil. Diário Oficial da República Federativa do Brasil, Brasília, DF, 05 de jan. de 1916. Disponível em: <http://www.planalto.gov.br/Ccivil_03/leis/L3071.htm〉. Acesso em: 12 jul. 2019.

. Lei n. 8.069, de 13 de jul. de 1990. Dispõe sobre o Estatuto da Criança e do Adolescente e dá outras providências. Diário Oficial da República Federativa do Brasil, Brasília, DF, 16 de jul. de 1990. Disponível em: 〈http://www.planalto.gov.br/ccivil_03/Leis/18069.htm〉. Acesso em: 27 jul. 2019.

. Lei n. 10.406, de 10 de jan. de 2002. Institui o Código Civil. Diário Oficial da República Federativa do Brasil, Brasília, DF, 11 de jan. de 2002. Disponível em: <http://www.planalto.gov.br/ccivil_03/Leis/2002/110406.htm〉. Acesso em: 16 jul. 2019.

. Superior Tribunal de Justiça. Recurso Especial n. ${ }^{\circ} 1674207$ PR 2017/0120487-1. Terceira Turma. Recorrente: R. P. dos S., por si e representando A. dos S. R., H. P. dos S. e K. P. dos S. Recorrido: Ministério Público do Estado do Paraná. Relator: Ministro Moura Ribeiro. Brasília, DF, 17 abr. 2018. Disponível em:

<https://ww2.stj.jus.br/processo/revista/inteiroteor/?num_registro=201701204871\&dt_publicacao=24 /04/2018>. Acesso em 26 jul 2019.

. Tribunal de Justiça do Distrito Federal e dos Territórios. Apelação Cível n. ${ }^{\circ}$

20070130040343. 5 Turma Cível. Apelante:. Apelado:. Relator: Desembargador João Egmont. Distrito Federal, DF. 09 fev. 2012. Disponível em:

$<$ https://pesquisajuris.tjdft.jus.br/IndexadorAcordaosweb/sistj?visaoId=tjdf.sistj.acordaoeletronico.bu scaindexada.apresentacao.VisaoBuscaAcordao\&nomeDaPagina $=$ buscaLivre2 \&buscaPorQuery $=1 \& b$ aseSelecionada=BASE_ACORDAOS\&filtroAcordaosPublicos $=$ false $\&$ camposSelecionados $=[$ ESPEL $\mathrm{HO}] \&$ argumentoDePesquisa $=00039714120078070013 \&$ numero $=\&$ tipoDeRelator $=$ TODOS\&dataFi $\mathrm{m}=\&$ indexacao $=\&$ ramoJuridico $=\&$ baseDados $=[$ TURMAS_RECURSAIS, \%20BASE_ACORDAOS_ IDR,\%20BASE_ACORDAOS]\& tipoDeNumero=NumAcordao\& tipoDeData=DataPublicacao\&emen ta $=\&$ filtroSegredoDeJustica $=$ false $\&$ desembargador $=\&$ dataInicio $=\&$ legislacao $=\&$ orgaoJulgador $=\& n u$ meroDaPaginaAtual=1\&quantidadeDeRegistros=20\&totalHits=1>. Acesso em 26 jul. 2019.

Tribunal de Justiça do Rio Grande do Sul. Apelação Cível n. ${ }^{\circ}$ 70070290283. $8^{\text {a }}$ Câmara Cível. Apelante: T.C.R. Apelado: M.P. Relator: Desembargador Luiz Felipe Brasil Santos. Porto Alegre, RS, 27 out. 2016. Disponível em:

<https://www 1.tjrs.jus.br/site_php/consulta/consulta_processo.php?nome_comarca=Tribunal\%20de $\% 20 J u s t i \%$ C3\%A7a\%20do $\% 20$ RS \&versao $=\& v e r s a o \_f o n e t i c a=1 \&$ tipo $=1 \&$ id_comarca $=700 \&$ num_p rocesso_mask $=\&$ num_processo $=70070290283 \&$ codEmenta $=7706337 \&$ temInt Teor $=$ true $>$. Acesso em: 25 jul. 2019.

CALDERÓN, Ricardo. Princípio da afetividade no Direito de Família [livro eletrônico]. 2. ed. Rio de Janeiro: Forense, 2017. Disponível em:

<https://integrada.minhabiblioteca.com.br/\#/books/9788530977153/cfi/6/2!/4/2@0:0>. Acesso em 18 jul. 2019.

CUNHA, Rogério Sanches. Nova lei amplia as hipóteses de perda do poder familiar. Ministério Público do Paraná. Disponível em: <http://www.crianca.mppr.mp.br/2018/09/39/LEGISLACAONova-lei-amplia-as-hipoteses-de-perda-do-poder-familiar.html>. Acesso em: 27 jul. 2019. 
DIAS, Maria Berenice. Manual de Direito das Famílias. 9. ed. São Paulo: Editora Revista dos Tribunais, 2013.

GAGLIANO, Pablo Stolze; PAMPLONA FILHO, Rodolfo. Novo Curso de Direito Civil: Direito de Família [livro eletrônico]. 7. ed. São Paulo: Saraiva, 2017. Disponível em:

<https://integrada.minhabiblioteca.com.br/\#/books/9788547217259/cfi/0〉. Acesso em: 12 jul. 2019.

GONÇALVES, Carlos Roberto. Direito Civil Brasileiro: Direito de Família [livro eletrônico]. 15. ed. São Paulo: Saraiva, 2018. Disponível em:

<https://integrada.minhabiblioteca.com.br/\#/books/9788547229320/cfi/0!/4/2@100:0.00>. Acesso em: 22 jul. 2019.

LÔBO, Paulo. Direito Civil: famílias [livro eletrônico]. 7. ed. São Paulo: Saraiva, 2017. Disponível em: <https://integrada.minhabiblioteca.com.br/\#/books/9788547209865/cfi/0>. Acesso em: 22 jul. 2019.

MADALENO, Rolf. Direito de Família [livro eletrônico]. 8. ed. Rio de Janeiro: Forense, 2018. Disponível em: <https://integrada.minhabiblioteca.com.br/\#/books/9788530980160/cfi/6/2!/4/2@0:0>. Acesso em: 15 jul. 2019.

NADER, Paulo. Curso de Direito Civil: Direito de Família [livro eletrônico]. 7. ed. Rio de Janeiro: Forense, 2016. Disponível em: <https://integrada.minhabiblioteca.com.br/\#/books/9788530968687/cfi/6/2!/4/2/2@0:0>. Acesso em: 22 jul. 2019.

PEREIRA, Rodrigo da Cunha. Responsabilidade Civil Pelo Abandono Afetivo. In: MADALENO, Rolf; BARBOSA, Eduardo (Coords.). Responsabilidade civil no Direito de Família [livro eletrônico]. São Paulo: Atlas, 2015. Disponível em: <https://integrada.minhabiblioteca.com.br/\#/books/9788597000689/cfi/0!/4/2@100:0.00>. Acesso em: 20 jul. 2019.

PIVA, Rui Carvalho. Famílias e Tutela dos Direitos Difusos [livro eletrônico]. São Paulo: Atlas, 2014. Disponível em:

<https://integrada.minhabiblioteca.com.br/\#/books/9788522489688/cfi/0!/4/2@100:0.00>. Acesso em: 10 jul. 2019.

RIZZARDO, Arnaldo. Direito de Família [livro eletrônico]. 10. ed. Rio de Janeiro: Forense, 2019. Disponível em:

<https://integrada.minhabiblioteca.com.br/\#/books/9788530983062/cfi/6/2!/4/2@0:0>. Acesso em: 30 jul. 2019.

TARTUCE, Flávio. Direito Civil: Direito de Família [livro eletrônico]. 13. ed. Rio de Janeiro: Forense, 2018. Disponível em: <https://integrada.minhabiblioteca.com.br/\#/books/9788530978235/cfi/6/2!/4/2@0:0>. Acesso em: 15 jul. 2019.

VENOSA, Sílvio de Salvo. Direito Civil: família [livro eletrônico]. 18. ed. São Paulo: Atlas, 2018. Disponível em:

<https://integrada.minhabiblioteca.com.br/\#/books/9788597014860/cfi/6/2!/4/2@0:0>. Acesso em: 22 jul. 2019. 